\title{
Conformational Lock and Dissociative Thermal Inactivation of Lentil Seedling Amine Oxidase
}

\author{
S. Zahra Moosavi-Nejad, Ali-Akbar Moosavi-Movahedi*, Mostafa Rezaei-Tavirani, \\ Giovanni Floris ${ }^{\dagger}$ and Rosaria Medda \\ Institute of Biochemistry and Biophysics, University of Tehran, Tehran, Iran \\ 'Department of Sciences Applied to Biosystems, University of Cagliari, Cagliari, Italy
}

Received 10 June 2002, Accepted 14 October 2002

\begin{abstract}
The kinetics of thermal inactivation of copper-containing amine oxidase from lentil seedlings were studied in a $100 \mathrm{mM}$ potassium phosphate buffer, pH 7, using putrescine as the substrate. The temperature range was between $47-60^{\circ} \mathrm{C}$. The thermal inactivation curves were not linear at 52 and $57^{\circ} \mathrm{C}$; three linear phases were shown. The first phase gave some information about the number of dimeric forms of the enzyme that were induced by the higher temperatures using the "conformational lock" pertaining theory to oligomeric enzyme. The "conformational lock" caused two additional dimeric forms of the enzyme when the temperature increased to $57^{\circ} \mathrm{C}$. The second and third phases were interpreted according to a dissociative thermal inactivation model. These phases showed that lentil amine oxidase was reversibly-dissociated before the irreversible thermal inactivation. Although lentil amine oxidase is not a thermostable enzyme, its dimeric structure can form "conformational lock," conferring a structural tolerance to the enzyme against heat stress.
\end{abstract}

Keywords: Active isomers, Amine oxidase, Conformational lock, Dimeric enzyme, Thermal inactivation

\section{Introduction}

Copper amine oxidases [amine: oxygen oxidoreductase (deaminating) (copper/TPQ-containing), EC 1.4.3.6] catalyze

\footnotetext{
*To whom correspondence should be addressed.

Tel: 98-21-6403957; Fax: 98-21-6404680

E-mail: moosavi@ibb.ut.ac.ir
}

\footnotetext{
Abbreviations: AO, amine oxidase; LSAO, lentil seedling amine oxidase; PSAO, pea seedling amine oxidase; TPQ, 6-hydroxydopaquinone; $\mathrm{T}_{\mathrm{opt}}$, optimum temperature.
}

the oxidation of primary amines with the formation of the corresponding aldehyde, ammonia, and hydrogen peroxide. Plant amine oxidases are soluble dimeric enzymes. Each monomer (molecular mass approximately $70 \mathrm{kDa}$ ) contains one $\mathrm{Cu}$ (II) center that is essential for enzyme redox activity, and one organic prosthetic group that is identified as 6hydroxydopa quinone (TPQ) (Janes et al., 1990). Most of the studies on AOs have concentrated on their physiological role (Maccarrone et al., 1991; Buffoni, 1995; Lyles, 1996), their mechanism of action (Agostinelli et al., 1997; Hevel et al., 1999; Padiglia et al., 2001), and the effects of some substrates (Lyles, 1995; Medda et al., 2000) and inhibitors (Befani et al., 1995; Padiglia et al., 1998). Although the crystal structures of various copper-containing amine oxidases have been determined (Cooper et al., 1992; Kumar et al., 1996; Wilce et al., 1997; Li et al., 1998), limited reports have been published on the importance of AOs subunits. For example, Aspergillus niger $\mathrm{AO}$, when treated with sodium n-dodecyl sulphate, SDS, dissociated into two subunits, which showed different mobility in native polyacrylamide gel electrophoresis (PAGE) (Frébort et al., 1995). The enzyme showed half-site reactivity with the carbonyl reagent phenylhydrazine, while each subunit could react with phenylhydrazine. This was probably caused by the conformational changes after binding of the inhibitor to any one of the active sites that lead to the inaccessibility of the second site for the inhibitor (allosteric effect) (Frébort et al., 1995). Moreover, dimeric-beef-plasma-amine oxidase was not readily dissociated by moderate denaturing conditions. These include acidic or basic solutions or low concentrations of guanidine hydrochloride, indicating very strong inter-subunit interactions (Achee et al., 1968); pig plasma amine oxidase exhibited no degree of flexibility, due to the independent rotation of the subunits in the nanosecond range (Massey and Churchich, 1979).

Protein oligomerization leads to the functional advantages of multivalency and high-binding strength, combining functions of different domains and increasing structure 
stabilization (Steif et al., 1993) without a considerable effect on the enzyme activity (Levi et al., 2000; for review see Engel and Kammerer, 2000). Moreover, oligomerization can induce new abilities or functions, such as binding to DNA (Jones, 1990), cytotoxicity (Canals et al., 2001), and a function as a hormone receptor (Wells, 1994). Some oligomeric enzymes may also contain a specific structure, called "conformational lock," which is defined as a complexity of inter-subunit contacts that, by progressive and stepwise breaks, leads to the separation of the inactive monomers. This structure gives additional structural/functional stability to oligomeric enzymes, due to the interaction of subunits and the formation of several active oligomeric forms (for review see Poltorak et al., 1998).

Allosteric relationships between the two subunits have never been observed in plant AOs (Padiglia et al., 2001); therefore, in the present study, we investigated the advantage(s) of the dimeric form in lentil amine oxidase. We report the kinetic thermal inactivation of LSAO in order to explain the "conformational lock" and importance of intersubunit interaction that confers thermal stability to the protein.

\section{Materials and Methods}

Materials LSAO was purified as previously described (Floris et al., 1983). Putrescine (1,4-diaminobutane) and horseradish peroxidase were purchased from the Sigma Chemical Co. (St. Louis, USA). All of the other chemicals were analytical grade commercial products.

Enzyme assay LSAO activity was tested by following the change in absorbance at $470 \mathrm{~nm}$, due to the guaiacol oxidation in the presence of hydrogen peroxide and horseradish peroxidase. The complete reaction mixture contained the following: $100 \mathrm{mM}$ potassium phosphate buffer $\mathrm{pH} 7.0 ; 13 \mathrm{mM}$ putrescine as a substrate; $0.1 \mathrm{U} / \mathrm{ml}$ horseradish peroxidase; and $0.5 \mathrm{mM}$ guaiacol in a final volume of $1 \mathrm{ml}$. The increase of absorbance at $470 \mathrm{~nm}$ was measured by a Shimadzu 3100 spectrophotometer. The resulting activity was directly used for analysis. Each activity value was the mean of at least three different determinations.

Thermal inactivation of LSAO The enzyme $\left(7.66 \times 10^{-9} \mathrm{M}\right.$; $1.15 \times 10^{-3} \mathrm{mg} / \mathrm{ml}$ ) was incubated in sealed vials in a $100 \mathrm{mM} \mathrm{K}$ phosphate buffer, $\mathrm{pH} 7.0$, at various temperatures $\left(47-60^{\circ} \mathrm{C}\right)$. An aliquot of enzyme solution was removed from the incubated samples, cooled immediately to $27^{\circ} \mathrm{C}$ in a water bath (a temperature at which the irreversible inactivation of the enzyme reached zero), then $750 \mu \mathrm{l}$ of the enzyme solution $\left(27^{\circ} \mathrm{C}\right)$ was assayed for enzyme activity. Cooling on ice was avoided to prevent any irreversible cold-induced conformational change. In order to prevent the dissociation of the enzyme dimer, or the formation of conformational changes due to the effect of the dilution, a small volume $(86 \mu \mathrm{l})$ of the assay stock solution (containing putrescine, peroxidase, and guaiacol) was added to $750 \mu$ l of the enzyme solution for the enzyme assays. The activities that were measured were used for drawing the thermal inactivation plots.
Optimum temperature determination $\mathrm{T}_{\mathrm{opt}}$ is defined as the maximum temperature at which the enzyme activity does not change during the incubation time (Segel, 1995). Therefore, the thermal inactivation curves (logarithm of remaining activity percentage versus incubation time) were drawn with an enzyme concentration of $1.5 \times 10^{-3} \mathrm{mg} / \mathrm{ml}\left(10 \times 10^{-9} \mathrm{M}\right)$ at different temperatures for $25 \mathrm{~min}$ in order to obtain $\mathrm{T}_{\mathrm{opt}}$.

Kinetics of thermal inactivation Data analysis was performed according to the dissociative-thermal-inactivation theory (Zaitzeva et al., 1996; Poltorak et al., 1998). For dimeric enzymes, it can be explained according to the following scheme:

$$
\begin{aligned}
& k_{1} \quad k_{\text {den }} \\
& E_{2} \leftrightarrow 2 E_{1} \rightarrow 2 E_{d e n} \\
& k_{-1}
\end{aligned}
$$

(Scheme 1)

where $E_{2}$ is the active dimer, $E_{1}$ is the deactive monomer (reversible dissociation), and $\mathrm{E}_{\mathrm{den}}$ is the inactive monomer (irreversible pathway). Because of some substantial structural alteration, $\mathrm{E}_{\mathrm{den}}$ is unable to be reassociated as $\mathrm{E}_{2}$. The $\mathrm{k}_{1}, \mathrm{k}_{-1}$ and $\mathrm{k}_{\mathrm{den}}$ values can be obtained by the plot $\ln \left(\mathrm{v} / \mathrm{v}_{0}\right)$ versus time under denaturing conditions (Zaitzeva et al., 1996). For obtaining the $\mathrm{k}$ values, a specific range of temperature (from 3 to $7^{\circ} \mathrm{C}$ over $\mathrm{T}_{\text {opt }}$ ) and a protein concentration around the numerical value of dissociation constant for dimeric protein are necessary. The kinetic curve of thermal inactivation of a dimeric enzyme under given conditions (see typical Fig. 1a) consists of two linear phases and an inflection point. The first phase corresponds to the non-steady-state kinetics of dissociation of the active dimer into deactive monomer. The second phase is related to the slow kinetics of irreversible inactivation of the monomers. This would then assume the following: (1) The process $E_{2} \rightarrow E_{2 d e n}$ is negligible ( $E_{2 \text { den }}$ is irreversible inactive dimer species, not shown in Scheme 1). (2) The production of $E_{d e n}$ is negligible until reaching the inflection point $(t=\tau)(\tau$ is the time of forming the inflection point) of the kinetic curve; it is possible to calculate the kinetic parameters and equilibrium constant from the equations 1-4 (Poltorak et al., 1998). Equation (1) is used for determination of $\mathrm{k}_{1}$ :

$$
2\left(\mathrm{v} / \mathrm{v}_{0}\right)-1 / 2 /\left(\mathrm{v} / \mathrm{v}_{0}\right)^{2}=3 / 2-\mathrm{k}_{1} \mathrm{t} \quad(\mathrm{t}<\tau)
$$

where $\mathrm{v}$ is the rate of catalytic reaction under saturation with substrate at time $\mathrm{t}$ before the inflection point $(\mathrm{t}<\tau) ; \mathrm{v}_{0}$ is the rate at time $t=0$. Equation (2) is used for calculation of $K_{d i s}$ based on the inflection point:

$$
\mathrm{K}_{\text {dis }}=\mathrm{k}_{1} / \mathrm{k}_{-1}=4\left[\mathrm{E}_{0}\right]\left(\mathrm{v}_{0}-\mathrm{v}_{\tau}\right)^{2} / \mathrm{v}_{0} \mathrm{v}_{\tau} \quad(\mathrm{t}<\tau)
$$

where $\mathrm{K}_{\mathrm{dis}}$ is the dissociation equilibrium constant from dimeric to monomeric form; $\left[\mathrm{E}_{0}\right]$ is the initial enzyme concentration; $\mathrm{v}_{\tau}$ is the rate of catalytic reaction at time $\tau$. The equation (2) should not be used at a high temperature $\left(\mathrm{k}_{\mathrm{den}}<\mathrm{k}_{1}\right)$ (Poltorak et al., 1998). $\mathrm{k}_{\mathrm{den}}$ can be calculated by the means of equation (3):

$$
\mathrm{k}_{\text {den }}=\mathrm{k}_{\text {eff }}\left(\mathrm{v}_{0}-\mathrm{v}_{\mathrm{t}}\right) / 2\left(\mathrm{v}_{0}-\mathrm{v}_{\tau}\right) \quad(\mathrm{t} \geq \tau)
$$

where $k_{\text {eff }}$ is the effective rate constant that is determined by the slope of the straight line (see typical Fig. 1a) at $t>\tau$ in the coordinate of the first-order equation $\left(\ln \left(\mathrm{v} / \mathrm{v}_{0}\right)\right.$ versus $\left.\mathrm{t}\right)$ (Poltorak $e t$ al., 1998).

In some cases (such as newly-isolated preparations), two-phase 

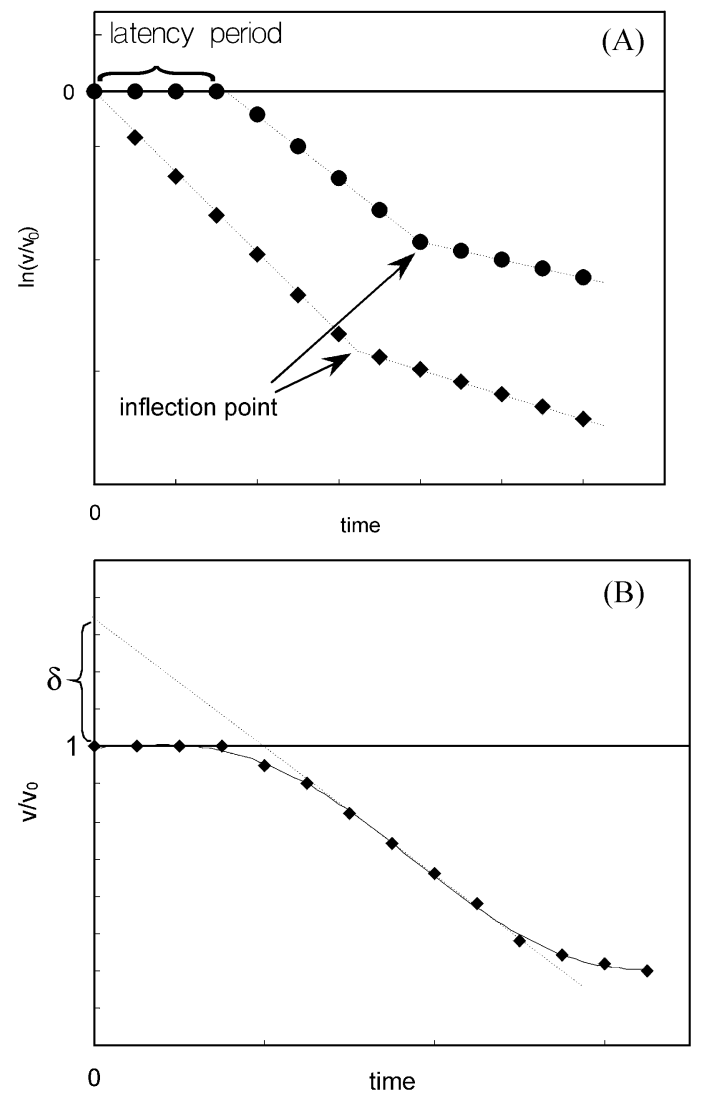

Fig. 1. Typical shapes of thermal inactivation curves for a dimeric enzyme that undergoes dissociative thermal inactivation without and with a latency period corresponding to the Scheme 1 and 2 respectively (see text); a) $\downarrow$, without latency period; O, with latency period; b) The graph shows the method for determining of $\delta$.

thermal inactivation curves of oligomeric enzymes may be preceded by a latency period (Fig. 1a). This would indicate that there are several active conformations that pertain to the "conformational lock" (Poltorak et al., 1998).

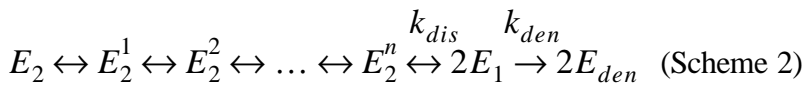

The " $n$ " value is defined as the minimal number of steps before the dissociation of the dimeric enzyme. It can be calculated using equation (4):

$$
\mathrm{n}=(0.13+\delta) /(0.13-0.05 \delta)
$$

where $\delta$ is a dimensionless parameter that is experimentally determined using graph $v / v_{0}$ versus $t$ (see typical Fig. $\left.1 b\right) .(1+\delta)$ is the ordinate intercept that is produced by a tangent to the inflection point of the kinetic curves.

\section{Results and Discussion}

Measurement of optimum temperature $\left(\mathbf{T}_{\text {opt }}\right)$ Figure 2 shows the thermal inactivation curve of LSAO. The $\mathrm{T}_{\mathrm{opt}}$ that is obtained is $50^{\circ} \mathrm{C}$ in 25 -min intervals.

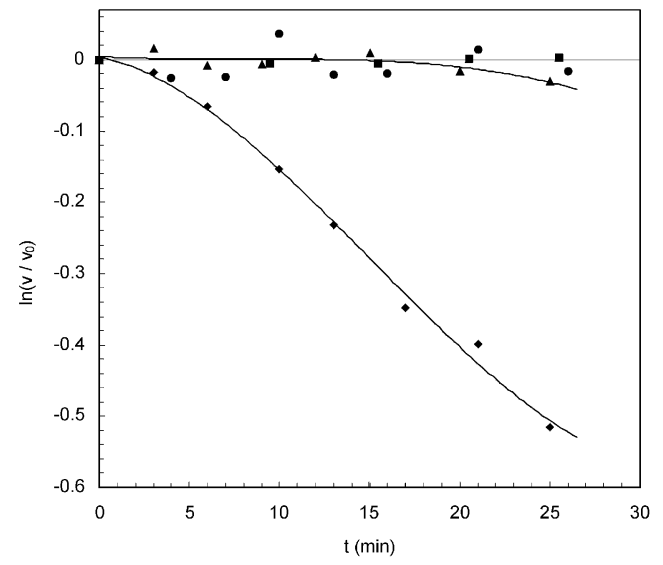

Fig. 2. The thermal inactivation curves for $\mathrm{LSAO}$ at the temperatures $47^{\circ} \mathrm{C}(\boldsymbol{O}), 50^{\circ} \mathrm{C}(\boldsymbol{\square}), 57^{\circ} \mathrm{C}(\boldsymbol{\Delta})$ and $60^{\circ} \mathrm{C}(\boldsymbol{\Delta})$ to obtain $\mathrm{T}_{\text {opt }}$. The concentration of LSAO is $1.5 \times 10^{-3} \mathrm{mg} / \mathrm{ml}$ $\left(10 \times 10^{-9} \mathrm{M}\right)$.

Kinetics of LSAO thermal inactivation Figure 3 shows the kinetics of thermal inactivation curves of LSAO at temperatures of 52 and $57^{\circ} \mathrm{C}$. Due to a lack of information about the dissociation constant of the LSAO dimer, we experimentally selected the suitable concentration, $7.66 \times 10^{-9}$ $\mathrm{M}$ of LSAO, in order to obtain a non-linear thermal inactivation curve. The curves are clearly nonlinear that contain three phases. Due to the equations $1-3, \mathrm{k}_{1}\left(\mathrm{~min}^{-1}\right)$, then $\mathrm{k}_{\mathrm{den}}\left(\mathrm{min}^{-1}\right)$, and $\mathrm{K}_{\mathrm{dis}}(\mathrm{M})$ were calculated using the second phase, the third phase, and the inflection point of Fig. 3a, respectively (see Table 1). The first phase was used to calculate the " $n$ " value (the minimal number of steps before the dissociation of the dimeric enzyme; see Table 2). Figure $3 \mathrm{~b}$ shows the kinetics of thermal inactivation curves $\left(\mathrm{v} / \mathrm{v}_{\mathrm{o}}\right.$ versus times) at 52 and $57^{\circ} \mathrm{C}$. The intercepts on the ordinate were used to calculate the "n" values (see Equation 4) that are tabulated on Table 2.

Dissociative thermal inactivation of LSAO Structural studies on dimeric proteins are often carried out by equilibrium denaturation methods (Neet and Timm, 1994; De Francesco et al., 1991; Sacchetta et al., 1993; Sanchez del Pino and Fersht, 1997). Functional studies have rarely been reported for studying the dimer denaturation via three-state (Scheme 3) (Aceto et al., 1992) or two-state (Scheme 4) mechanisms as follows:

$$
\begin{gathered}
K_{1} \quad K_{2} \\
N_{2} \leftrightarrow 2 I \leftrightarrow 2 D \\
K_{1} \\
N_{2} \leftrightarrow 2 D
\end{gathered}
$$

(Scheme 3)

(Scheme 4)

where $\mathrm{N}_{2}$ is the dimeric native protein, $\mathrm{I}$ is the native-like monomer, and $\mathrm{D}$ is the denatured monomer. Poltorak and coworkers (Poltorak et al., 1998) studied the enzyme activity in order to gain additional knowledge on the oligomeric enzyme behavior via the denaturation study. They suggested the 

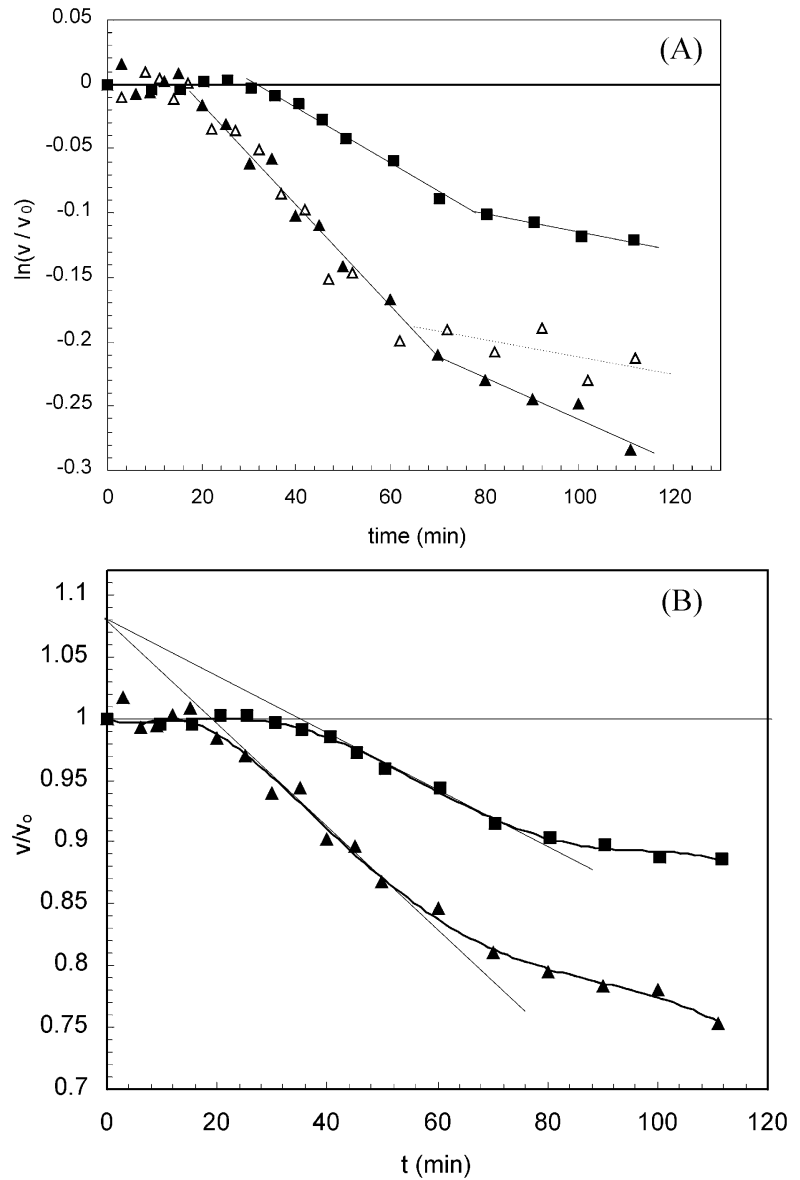

Fig. 3. Kinetics of thermal inactivation of LSAO at the temperatures $52^{\circ} \mathrm{C}(\boldsymbol{\square})$ and $57^{\circ} \mathrm{C}(\boldsymbol{\Delta})$; a) $\ln \left(\mathrm{v} / \mathrm{v}_{0}\right)$ versus time, b) $\mathrm{v} / \mathrm{v}_{0}$ versus time. The concentration of LSAO is $7.66 \times 10^{9} \mathrm{M}$ for solid lines. Dashed line shows the same curve at $57^{\circ} \mathrm{C}$ when the enzyme concentration was $8.5 \times 10^{-9} \mathrm{M}(\triangle)$.

"dissociative thermal inactivation" for the dimeric enzymes (Scheme 1), which is a similar pattern to the three-state denaturation model (Scheme 3) (Neet and Timm 1994). The thermal inactivation of enzymes is usually used for measuring $\mathrm{T}_{\text {opt }}$ (Segel, 1995), or for estimating their thermal stability (Harris and Davidson, 1994; Segel, 1995; Bai et al., 1997). The logarithm of the remaining activity percentage is primarily assumed to be a linear function of the time at any temperature, even if it is not linear (Sriprapundh et al., 2000). At particular ranges of temperature and enzyme concentration, the non-linear behavior of the thermal inactivation of oligomeric enzyme is imposed, and contains large structural information (Zaitzeva et al., 1996; Poltorak et al., 1998).

As shown in Fig. 3, the second linear phases of the curves belong to dissociation behavior at 52 and $57^{\circ} \mathrm{C}$ as follows:

$$
\begin{gathered}
K_{d i s} \\
E_{2} \leftrightarrow 2 E_{1}
\end{gathered}
$$

(Scheme 5)
Table 1. Rate constants $\left(\mathrm{k}_{1}\right.$ and $\left.\mathrm{k}_{\mathrm{den}}\right)$ and dissociative equilibrium constant $\left(\mathrm{K}_{\mathrm{dis}}\right)$ of dissociative thermal inactivation of LSAO. The values were obtained from Fig. 3a according to Scheme 1 using Equations 1-3.

\begin{tabular}{cccc}
\hline $\mathrm{t}\left({ }^{\circ} \mathrm{C}\right)$ & $\mathrm{k}_{1}\left(\mathrm{~min}^{-1}\right)$ & $\mathrm{K}_{\mathrm{dis}}(\mathrm{M})$ & $\mathrm{k}_{\mathrm{den}}\left(\mathrm{min}^{-1}\right)$ \\
\hline 52 & $1.752 \times 10^{-3}$ & $3.064 \times 10^{-10}$ & $3.52 \times 10^{-4}$ \\
57 & $4.716 \times 10^{-3}$ & $1.352 \times 10^{-9}$ & $8.92 \times 10^{-4}$ \\
\hline
\end{tabular}

Table 2. " $\delta$ " and "n" values for LSAO at the temperatures 52 and $57^{\circ} \mathrm{C}$. The $\delta$ values were taken from Fig. $3 \mathrm{~b}$ and inserted in Equation 4 to calculate " $n$ " values.

\begin{tabular}{ccc}
\hline Temperature $\left({ }^{\circ} \mathrm{C}\right)$ & $\delta$ & $\mathrm{n}$ \\
\hline 52 & 0.08 & $1.7 \approx 2$ \\
57 & 0.08 & $1.7 \approx 2$ \\
\hline
\end{tabular}

where $\mathrm{K}_{\mathrm{dis}}$ of the reaction depends on the incubation temperature (Table 1). The deactive monomers can then be irreversibly denatured into an inactive form. Results of the last linear phase of plots in Fig. 3 are as follows:

$$
\begin{gathered}
k_{d e n} \\
E_{2} \leftrightarrow E_{d e n}
\end{gathered}
$$

(Scheme 6)

In order to confirm the dissociative inactivation, the dependence of thermal inactivation curve to the enzyme concentration (Fig. 3a) as a common property of any reversible dissociation needs to be shown (Poltorak et al., 1998; Aceto et al., 1992).

"Conformational lock" in LSAO Figures 3 (a, b) shows the "latency period" during the thermal inactivation for LSAO. The latency period pertains to the existence of processes that are due to some possible changes in the dimeric enzyme structure, but no significant effect on active centers, which indicates that there is more than one dimeric form. The minimal number of steps before the dissociation of $E_{2}$ into catalytically-inactive monomers for LSAO is defined as ' $n$ '. As reported, 'n' may vary from 2 to 5 (Poltorak et al., 1998). For LSAO $n=2$ (see Table 2), but it contains three dimeric forms $\left(\mathrm{E}_{2}, \mathrm{E}_{2}^{1}\right.$, and $\left.\mathrm{E}_{2}^{2}\right)$ :

$$
E_{2} \leftrightarrow E_{2}^{1} \leftrightarrow E_{2}^{2} \leftrightarrow k_{d i s} k_{d e n} E_{1} \rightarrow 2 E_{d e n}
$$

(Scheme 7)

To explain these experimental data, the hypothesis of "conformational lock" has been proposed and used for the interpretation of the non-liner thermal inactivation, as reported for several oligomeric enzymes (Poltorak et al., 1998). To confirm the conformational lock and dissociative-thermal inactivation, one should look for two characteristics in the crystal structure of the enzyme. These characteristics are as follows: (a) The existence of several (groups of) contacts between the two subunits for confirming conformational lock. (b) The existence of at least one of the (groups of) contacts that is necessary for enzymatic activity in order to explain the 
dissociative inactivation (Poltorak et al., 1998). Since PSAO has an almost identical structure to LSAO with a 91-95\% identity in amino acid sequences (Moosavi-Nejad et al., 2001), we then used the X-ray data of PSAO as a model for the analysis of the LSAO structure.

PSAO has two structurally-identical subunits; each is composed of three domains, called $\mathrm{D}_{2}, \mathrm{D}_{3}$, and $\mathrm{D}_{4}$ (Kumar et al., 1996). The two subunits have similar interactions, so that some amino acids from one subunit are close to the other. Therefore, it is unlikely that the monomeric form can be catalytically active. Three types of inter-subunit contacts in PSAO can be observed (Kumar et al., 1996):

(a) Two arms of each monomer are extended to another monomer that is very near to its active site; the side chain of Trp482 that is located on one of the two arms is hydrogenbonded to the carboxyl group of Asp443 in another subunit, the residue between the two active site residues His442 and His444 (Kumar et al., 1996). This may explain the reason why only the dimeric form of LSAO is catalytically active (Padiglia et al., 2001).

(b) The hydrophobic interaction area between the $\mathrm{D}_{4}$ domain of monomers may have an important role to protect radical catalytic intermediates, such as semiquinone against the accessibility of solvents (Kumar et al., 1996).

(c) On the $\mathrm{D}_{4}$ domains a small $\beta$-sheet is made by a short part of each monomer.

The two first contacts are essential for the enzyme activity. The latter contact (the small $\beta$-sheet) may not have a drastic effect on the PSAO activity, because it is located far from the active site and lies in a separated edge of the molecule. Moreover, there is only one free cysteinyl residue that is near the C-terminal of each monomer they are very close to each other (Kumar et al., 1996). At higher temperatures, where the degree of freedom of rotation and movement of side chains is increased, the possibility for these cysteine residues to make a disulfide bridge is suspected. This may provide a viable explanation for the existence of a more dimeric form of LSAO. Obviously, alternative mechanisms might also be hypothesized. Three types of inter-subunit contacts in LSAO and their interactions demonstrate the possibility of a multistep opening of the "conformational lock," and show the cause for the inactivation of the monomeric enzyme. We previously reported two active conformations for LSAO $\left(\mathrm{E}_{2}\right.$ and $\mathrm{E}_{2}^{1}$ ), up to $50^{\circ} \mathrm{C}$ using an Arrhenius plot and differentialscanning calorimeter (DSC) profile (Moosavi-Nejad et al., 2001). Here, our results also show the third dimeric form $\left(E_{2}^{2}\right.$, see Scheme 7) of LSAO between $50-57^{\circ} \mathrm{C}$.

Therefore, the dimeric structure confers to LSAO a structural potency to tolerate higher temperatures, due to the "conformational lock". A reversible-dissociative-thermal inactivation (three-state of denaturation) can cause an extra resistance of the enzyme against higher temperatures. Therefore, LSAO can relatively retain its structure and activity at heat stress, although it is not a thermostable enzyme.
Acknowledgments The financial support that was provided from the Research Council of the University of Tehran is gratefully appreciated. This study was also partly supported by the C.N.R. Target Project on Biotechnology Funds, Italy.

\section{References}

Aceto, A., Caccuri, M., Sacchetta, P., Bucciarelli, T., Dragani, B., Rosato, N., Federici, G. and Di Ilio, C. (1992) Dissociation and unfolding of Pi-class glutathione transferase. Biochem. J. 285, 241-245.

Achee, F. M., Chervenka, C. H., Smith, R. A. and Yasunobu, K. T. (1968) Amine oxidase. XII. The association and dissociation and number of subunits of beef plasma amine oxidase. Biochemistry 7, 4329-4335.

Agostinelli, E., De Matteis, G., Sinibaldi, A., Mondovi, B. and Morpurgo, L. (1997) Reactions of the oxidized organic cofactor in copper-depleted bovine serum amine oxidase. Biochem. J. 324, 497-501.

Bai, J. H., Wang, H. J., Liu, D. S. and Zhou, H. M. (1997) Kinetics of thermal inactivation of lactate dehydrogenase from rabbit muscle. J. Protein Chem. 16, 801-807.

Befani, O., Shiozaki, T. S., Turini, P., Gerosa, P. and Mondovi, B. (1995) Inhibition of diamine oxidase activity by metronidazole. Biochem. Biophys. Res. Commun. 212, 589-594.

Buffoni, F. (1995) Semicarbazide-sensitive amine oxidases: some biochemical properties and general considerations. Prog. Brain. Res. 106, 323-331.

Canals, A., Pous, J., Guasch, A., Benito, A., Ribó, M., Vilanova, M. and Coll, M. (2001) The structure of an engineered domain-swapped ribonuclease dimer and its implications for the evolution of proteins toward oligomerization. Structure (Camb) 9, 967-976.

Cooper, R. A., Knowles, P. F., Brown, D. E., McGuirl, M. A. and Dooley, D. M. (1992) Evidence for copper and 3,4,6trihydroxyphenylalanine quinone cofactors in an amine oxidase from the gram-negative bacterium Escherichia coli $K-12$. Biochem. J. 288, 337-340.

De Francesco, R., Pastore, A., Vecchio, G. and Cortese, R. (1991) Circular dichroism study on the conformational stability of the dimerization domain of transcription factor LFB1. Biochemistry 30, 143-147.

Engel, J. and Kammerer, R. A. (2000) What are oligomerization domains good for? Matrix Biol. 19, 283-288.

Floris, G., Giartosio, A. and Rinaldi, A. (1983) Diamine oxidase from Lens esculenta seedlings: purification and properties. Phytochemistry 22, 1871-1874.

Frébort, I., Toyama, H., Matsushita, K., and Adachi, O. (1995) Half-site reactivity with p-nitrophenylhydrazine and subunit separation of the dimeric copper-containing amine oxidase from Aspergillus niger. Biochem. Mol. Biol. Int. 36, 1207-1216.

Harris, T. K. and Davidson, V. L. (1994) Thermal stability of methanol dehydrogenase is altered by the replacement of enzyme-bound $\mathrm{Ca}^{2+}$ with $\mathrm{Sr}^{2+}$. Biochem. J. 303, 141-145.

Hevel, J. M., Mills, S. A. and Klinman, J. P. (1999) Mutation of a strictly conserved, active-site residue alters substrate specificity and cofactor biogenesis in a copper amine oxidase. Biochemistry 38, 3683-3693. 
Janes, S. M., Mu, D., Wemmer, D., Smith, A. J., Kaur, S., Maltby, D., Burlingame, A. L. and Klinman, J. P. (1990) A new redox cofactor in eukaryotic enzymes, 6-hydroxydopa at the active site of bovine serum amine oxidase. Science 248, 981-987.

Jones, N. (1990) Transcriptional regulation by dimerization: two sides to an incestuous relationship. Cell 61, 9-11.

Kumar, V., Dooley, D. M., Freeman, H. C., Guss, J. M., Harvey, I., McGuirl, M. A., Wilce, M. C. and Zubak, V. M. (1996) Crystal structure of a eukaryotic (pea seedling) coppercontaining amine oxidase at 2.2 A resolution. Structure 4, 943955.

Levi, V., Rossi, L. P., Castello, P. R. and Gonzales Flecha, F. L. (2000) Oligomerization of the plasma membrane calcium pump involves two regions with different thermal stability. FEBS Letter 483, 99-103.

Li, R., Klinman, J. P. and Mathews, F. S. (1998) Copper amine oxidase from Hansenula polymorpha, the crystal structure determined at 2.4 A resolution reveals the active conformation. Structure 6, 293-307.

Lyles, G. A. (1995) Substrate-specificity of mammalian tissuebound semicarbazide-sensitive amine oxidase. Prog. Brain. Res. 106, 293-303.

Lyles, G. A. (1996) Mammalian plasma and tissue-bound semicarbazide-sensitive amine oxidases: biochemical, pharmacological and toxicological aspects. Int. J. Biochem. Cell Biol. 28, 259-274.

Maccarrone, M., Rossi, A., Avigliano, L. and Finazzi Agrò, A. (1991) Activity and expression of diamine oxidase in lentil seedlings under different growth conditions. Plant Science 79, 51-55.

Massey, J. B. and Churchich, J. E. (1979) Nanosecond spectroscopy of dimeric enzyme: plasma amine oxidase. Biophys. Chem. 9, 157-162.

Medda, R., Padiglia, A., Lorrai, A., Finazzi Agrò, A. and Floris, G. (2000) Arginine and ornithine oxidation catalyzed by lentil seedling copper-amine oxidase. J. Protein Chem. 19, 51-57.

Moosavi-Nejad, S. Z., Rezaei-Tavirani, M., Padiglia, A., Floris, G. and Moosavi-Movahedi, A. A. (2001) Amine oxidase from lentil seedlings: energetic domains and effect of temperature on activity. J. Protein Chem. 20, 405-411.

Neet, K. E. and Timm, D. E. (1994) Conformational stability of dimeric proteins: quantitative studies by equilibrium denaturation. Protein Sci. 3, 2167-2174.

Padiglia, A., Medda, R., Bellelli, A., Agostinelli, E., Morpurgo, L., Mondovi, B., Finazzi Agrò, A. and Floris, G. (2001) The reductive and oxidative half-reactions and the role of copper ion in plant and mammalian copper-amine oxidases. Eur. J. Inorg. Chem. 35-42.

Padiglia, A., Medda, R., Pedersen, J. Z., Lorrai, A., Peè, P., Frébor, I. and Floris, G. (1998) Inhibitors of plant copper amine oxidases. J. Enzyme Inhibition 13, 311-325.

Poltorak, O. M., Chukhray, E. S. and Torshin, I. Y. (1998) Dissociative thermal inactivation, stability and activity of oligomeric enzymes. Biochemistry (Moscow) 63, 303-311.

Sacchetta, P., Aceto, A., Bucciarelli, T., Dragani, B., Santarone, S., Allocati, N. and Di Ilio, C. (1993) Multiphasic denaturation of glutathione transferase B1-1 by guanidinium chloride. Role of the dimeric structure on the flexibility of the active site. Eur. $J$. Biochem. 215, 741-745.

Sanchez del Pino, M. M. and Fersht, A. R. (1997) Nonsequential unfolding of the alpha/beta barrel protein indole-3-glycerolphosphate synthase. Biochemistry 36, 5560-5565.

Segel, I. H. (1995) Enzyme Kinetics, pp. 926-942, John Wiley \& Sons, Inc., New York.

Sriprapundh, D., Vieille, C. and Zeikus, J. G. (2000) Molecular determinants of xylose isomerase thermal stability and activity: analysis of thermozymes by site-directed mutagenesis. Protein Eng. 13, 259-265.

Steif, C., Weber, P., Hinz, H., Flossdorf, J., Cesareni, G. and Kokkinidis, M. (1993) Subunit interactions provide a significant contribution to the stability of the dimeric four-A-Helicalbundle protein ROP. Biochemistry 32, 3867-3876.

Wells, J. A. (1994) Structural and functional basis for hormone binding and receptor oligomerization. Curr. Opin. Cell Biol. 6, 163-173.

Wilce, M. C., Dooley, D. M., Freeman, H. C., Guss, J. M., Matsunami, H., McIntire, W. S., Ruggiero, C. E., Tanizawa, K. and Yamaguchi, H. (1997) Crystal structures of the coppercontaining amine oxidase from Arthrobacter globiformis in the holo and apo forms, implications for the biogenesis of topaquinone. Biochemistry 36, 16116-16133.

Zaitzeva, E. A., Chukrai, E. S. and Poltorak, O. M. (1996) Thermostability of yeast hexokinase and yeast glucose-6phosphate dehydrogenase. Appl. Biochem. Biotech. 61, 67-74. 